\title{
1 Pelletization of torrefied biomass with solid and liquid bio-additives
}

2 R. García, M.P. González-Vázquez, A.J. Martín, C. Pevida*, F. Rubiera

3 Instituto Nacional del Carbón, INCAR-CSIC. c/Francisco Pintado Fe, 26. 33011

4 Oviedo. Spain

$5 \quad *$ corresponding author e-mail: cpevida@incar.csic.es

6 Abstract

7 Biomass commonly presents poor physical properties and low energy density that need

8 to be enhanced. Torrefaction and densification are two of the most suitable techniques

9 to this aim. In this work the pelletization of torrefied pine, blended with solid (raw pine

10 and grape pomace) and liquid (glycerol) additives at low temperature (i.e., $40-80{ }^{\circ} \mathrm{C}$ )

11 was carried out in a continuous bench-scale flat die pellet mill that simulates the

12 features of a production-scale system. Among all the tested blends, four formulations

13 fulfilled the requirements of the EN-Plus and ISO 17225-2-Industrial Pellets quality standards, which make them suitable fuels for both residential heating systems and power plant boilers. The produced pellets hold higher heating values between 18.821.7 MJ/kg, energy denisties in the range $12.18-15.33 \mathrm{GJ} / \mathrm{m}^{3}$ and optimum physical properties $\left(\mathrm{L}=20-25 \mathrm{~mm}, \varnothing=6.1-6.2 \mathrm{~mm}, \rho_{\mathrm{p}}=1.1-1.2 \mathrm{~g} / \mathrm{cm}^{3}\right)$, in line with the reference pine pellets.

A preliminary economic analysis was pursued proving that the improvements observed in formulations of torrefied pine, with $20 \mathrm{wt} . \%$ glycerol and with $10 \mathrm{wt} . \%$ grape pomace and $10 \mathrm{wt} . \%$ glycerol, may provide savings up to $20 \%$ in construction and transport costs.

Keywords

24 Biomass; torrefaction; pelletization; waste biomass; densification 


\section{Introduction}

Fossil fuels have been mankind's main energy source for decades and currently represent $85 \%$ of the primary energy consumption [1]. However, concerns about their non-renewability and the effect of their greenhouse gases emissions on global warming [2], have turned the attention towards alternative feedstocks that can complement or partially replace fossil fuels as primary energy source. Some advantages of biomass like its renewability, autonomy [3], $\mathrm{CO}_{2}$ life-cycle neutrality [4], and low $\mathrm{NO}_{\mathrm{x}}$ and $\mathrm{SO}_{2}$ emissions [5], make it a sustainable resource highly suited to this end. Yet its use on a large scale is commonly handicapped by its poor physical properties [6]. Hence, the need for techniques such as torrefaction and densification by pelletization to enhance its energy density, and reduce transport and handling costs [7], so as to make biomass economically competitive against other fuels.

During the torrefaction process, biomass samples are subjected to soft thermal treatment (typically $200-300{ }^{\circ} \mathrm{C}$ during $0.5-3$ hours) [8] under an inert or air-impoverished atmosphere [9]. Under such operating conditions, light volatiles are released and a concentrated, hydrophobic and easily grindable carbon product is obtained [10]. Due to the relative increase in the carbon content of the sample, torrefied biomass also shows increased higher heating values (HHV) [11]. In contrast, biomass bulk density values decrease slightly after torrefaction, so a combination of torrefaction and densification is required to obtain fuels with acceptable energy density values [12].

There are two main pellet quality classifications according to their use. They impose different requirements in raw matter origin and pellet properties. Pellets manufactured for residential heating systems are standardized by EN-Plus [13], which presents three sub-qualities (A1, A2, and B) for domestic boilers, devices above 50kW or district heating, and combined heat and power plants, respectively. On the other hand, the less 
restrictive Industrial Quality Pellets normative [14] includes three qualities (I1, I2, and I3) aimed for industrial-scale power plants. I2 is the pellet quality most traded in the world and focuses on coal-biomass co-firing plants [15].

Many works can be found in the literature dealing with raw biomass pelletization and using different binders. In addition, most of these works are conducted in single pellet press (SPP) devices. However, far fewer number of works consider torrefied biomass as feedstock and the number decreases further if pelletization is undertaken with continuous equipment at bench, pilot or industrial scale.

During torrefied matter pelletization in SPP, some vegetable liquids like rapeseed [16], castor bean [17] or sunflower [18] oils were tested as lubricants, while solids such as lignin, usually reported as natural binder [17], starch [19], different amino-acids [18] or hydrothermally carbonized char [20] were proposed as binders.

Among the works that have performed the pelletization of torrefied biomass in a continuous mode at bench-scale, one can cite that of Pirraglia et al., who tested the pelletization capability of eucalyptus chips in a flat die pellet mill using 2 vol. $\%$ of dried distilled grains (rich in fats and starch) and soybean as binders [21]. Shang et al. studied the pelletization of torrefied pine chips in a SPP and scaled-up the best results to a bench-scale flat die pellet mill using 2 wt.\% of rapeseed oil as lubricant [16]. ArteagaPérez et al. tested the pelletization capability of eucalyptus globulus with 1 wt.\% starch as binder in a $300 \mathrm{~kg} / \mathrm{h}$ pelletizer [22].

It has been stated that the pellets produced in SPP are different from those attained in continuous pelletizers. In a SPP pellets are not produced continuously and the flow of biomass into the openings of the press channels cannot be simulated exactly as it is in a real pellet press. The optimized pelletization conditions regarding the pellet properties from a SPP may not work for a continuous bench-scale pelletizer [16]. 
The present study focuses on testing the pelletization properties of torrefied pine in a continuous flat die pellet press, which simulates the features of a production-scale pelletizer, at low temperature conditions, which avoid excessive drying of the sample [23] and the release of light volatiles during pelletization.

The torrefaction conditions employed in this work can enhance some characteristics of the torrefied product such as the relative carbon content, grindability characteristics or higher heating value but also induce a higher hydrophobicity and degradation of the lignin component. Thus, the pelletization of torrefied biomass may require the addition of binders, that compensate the loss of lignin, and lubricants, to counteract the hydrophobic character of the torrefied matter. In this work both solid (pine sawdust and dried grape pomace) and liquid (glycerol) additives that presented promising results in experiments undertaken in a SPP [24] will be used for the pelletization of torrefied pine in a continuous pellet press.

Raw pine is a fuel similar to its torrefied counterpart, easily mixable and with higher lignin content. Grape pomace is a cheap and plentiful by-product of the wine production that presents a high lignin content (> 50\%) [25]. Glycerol has been used as a lubricant for raw biomass pelletization [26-28], but its addition to torrefied biomass has not been reported as yet. Glycerol is a highly energetic $(\approx 18 \mathrm{MJ} / \mathrm{kg})$, organic, dense liquid that reduces the fuel-die friction in the pellet mill. It has been claimed that the combustion of waste wood briquettes with absorbed glycerol decreases the formation of ash and the emissions of $\mathrm{NO}_{\mathrm{x}}$ [29]. It is widely available as a by-product of biodiesel production, where 1 ton of crude glycerol is obtained for each 10 ton of biodiesel [30]. Binary and ternary blends were tested in this work using durability as the main quality criterion. The formulations that offered adequate durability values were subjected to an extensive experimental testing campaign to determine their physical properties, higher 
heating value, energy density, and combustion behavior. These formulations were compared with a reference raw pine sample and the requirements of international standards. Besides, a brief economic evaluation of the obtained samples was carried out with regards to production cost and potential savings that might be achieved as a consequence of the enhanced properties of the torrefied biomass pellets' formulations.

The new formulations evaluated in this work can produce high-quality torrefied pine pellets that accomplish international quality standards. Raw pine, grape pomace, and glycerol are good additive candidates due to the binder and/or lubricant role in the pelletization process. Moreover, the preliminary economic evaluation has proved that the observed enhancement in the characteristics of selected formulations makes them competitive to traditional raw matter pellets, particularly for high-consumption installations and/or long transport distances.

\section{Materials and methods}

\subsection{Samples, additives and conditions}

Pine is a plentiful softwood fuel that was supplied in the form of chips that were dried at $35^{\circ} \mathrm{C}$ during 72 hours in a dry room and then ground and sieved between 1-4 mm (PIN) in a Retsch SM2000 mill. This size permits a homogeneous degree of torrefaction and avoids the blockage of the pelletizer die that may take place when small-size particles $(<1 \mathrm{~mm})$ are used during pelletization. The PIN sample was torrefied at $280{ }^{\circ} \mathrm{C}$ for 1 hour in a Nabertherm RSR $120-750 / 11$ rotary tube furnace using $\mathrm{N}_{2}$ as carrier gas with a flow rate of $3 \mathrm{~L} / \mathrm{min}$ to obtain a torrefied pine sample (PINT) with enhanced grinding and combustion properties [31]. At the furnace exit, the tars produced were collected by forcing them to pass through a cold trap filled with isopropyl alcohol. 
124 Grape pomace (GP) is a lignin-rich biomass solid waste that resulted to be an effective natural binder as it enhanced the durability of torrefied pine in previous SPP tests [24].

126 GP was dried at $35{ }^{\circ} \mathrm{C}$ for 72 hours and then ground and sieved between $0.1-1 \mathrm{~mm}$ in order to yield a mixable "flour" that could serve as a ligand. Glycerol (GLY) was also used in this work as it could serve the dual purpose of acting as binder and lubricant in the pelletization of torrefied biomass. In this work GLY was first mixed with distilled water in a $50 \mathrm{wt} . \%$ ratio, then stirred until completely homogenized and the resulting mixture was sprayed onto the torrefied sample in the quantity required for each formulation.

The results of the proximate and ultimate analyses, Higher Heating Value (HHV), Bulk Density (BD) and Energy Density $\left(\eta_{e}\right)$ of the samples used are given in Table 1. Moisture and ash contents were determined in a LECO TGA701, as indicated in the ASTM D7582-10 standard, volatile matter content was determined in a Heraeus Electro-Nite muffle furnace, in accordance with the ISO 562 standard, CHN contents content was determined in a LECO S632, in accordance with the ASTM D4239 standard. Higher heating values (HHV) were evaluated in an IKA-Werke C4000 adiabatic calorimeter following the ASTM D5865 standard. Oxygen and fixed carbon (FC) were determined by difference. Energy density was calculated as the ratio between the higher heating value and the bulk density.

The samples were denoted according to the component acronym and mass composition, i.e., the solid component abbreviation (PINT) followed by PIN or GP depending on the solid additive in the blend, then the mass percentage of the main fuel (PINT), followed by the mass percentages of the solid (PIN or GP) and the liquid (GLY) additives. For instance, PINT 100/0/20 is a sample consisting of PINT with 20\% GLY; PIN 100/0/0 
(reference sample) refers to raw PIN pellets; PINT-PIN 75/25/10 is a sample consisting of $75 \%$ PINT, $25 \%$ PIN and $10 \%$ GLY, all of them in wt. $\%$. It must be noted that GLY content is expressed as a fraction of the overall mass of the solid components, i.e., $20 \%$ of GLY indicates $20 \mathrm{~g}$ of glycerol for each $100 \mathrm{~g}$ of solid biomass (PINT or PINT+PIN/GP), this is why the sum may be higher than $100 \%$ in some cases. The composition of each sample is detailed in Table 2.

\subsection{Pelletization experiments and abrasion index determination}

The components required for each formulation were mixed and homogenized for 2 hours in a Lleal Process V solid mixer and dried at $35{ }^{\circ} \mathrm{C}$ during 72 hours. The moisture content of the samples was obtained by spraying distilled water onto the biomasses. Pelletization tests were carried out in an Amandus Kahl 14-175 flat die pellet press (Figure 1). This device is equipped with two steel rollers and a die with bores of $6 \mathrm{~mm}$ diameter and $30 \mathrm{~mm}$ length. The press can produce up to $50 \mathrm{~kg} / \mathrm{h}$ of pellets by providing a pressure of 13 bar thanks to the steel rollers. Two knives are located $35 \mathrm{~mm}$ under the die to cut the pellets to the desired size. Nevertheless, as it will be discussed later, this temperature is reached. In most cases this temperature lies between $75-85^{\circ} \mathrm{C}$ but it fluctuates slightly as a function of each studied sample. The temperature range varies from $40{ }^{\circ} \mathrm{C}$, where most formulations are hard enough to comply with the standard 
norms for durability, to $80-85^{\circ} \mathrm{C}$, thereby providing further knowledge of the influence of temperature on the process. Moisture was determined for every sample using an Ohaus MB45 moisture analyzer.

Durability (DUR) was the primary quality criterion adopted for this work. It is a property commonly used to measure the resistance of a fuel to abrasion and is influential in transport, handling and storage. The abrasion index (AI) was obtained by subjecting $100 \mathrm{~g}$ of pellets to 3000 turns at $35 \mathrm{rpm}$ in a rotating drum, as described elsewhere [32]. The mass of the material remaining after testing was sieved through a 2 $\mathrm{mm}$ sieve, so that the abrasion index (AI), and the durability of the sample (DUR) could be calculated as follows [33]:

$$
D U R=100-A I=\left[1-\left(\frac{M_{0}-M_{R}}{M_{0}}\right)\right] \cdot 100
$$

where $M_{0}$ is the initial sample mass and $M_{R}$ the mass retained on the $2 \mathrm{~mm}$ sieve.

Different quality indicators have been considered in the literature depending on the durability values, the type of biomass and its ulterior application. Adapa et al. considered that high quality alfalfa pellets must have durability values over $80 \%$ [34]. Richards et al. stated that durability values of at least $95 \%$ should be reached for coal briquettes to be considered as acceptable [35]. The EN-Plus European standard established a minimum of $98 \%$ durability for the A1 pellet class and $97.5 \%$ for the A2 and B classes [36]. On the other hand, normative for industrial-use pellets [37] establishes minimum durability of $96.5,97$ and $97.5 \%$ for I3, I2, and I1qualities, respectively.

In this work, the EN-Plus A2 requirement of $97.5 \%$ was adopted as the minimum DUR value for sample acceptability, given that it also qualifies for any industrial quality. Samples that presented adequate DUR values were subjected to an extended analytical procedure that included proximate, ultimate and calorific value analyses, as well as 
determination of physical properties such as particle size, particle density $\left(\rho_{\text {part }}\right)$, durability (DUR) and bulk density (BD). The energy density $\left(\eta_{\mathrm{e}}\right)$ and the combustion behavior of the obtained pellets were also determined, and the results were compared to those obtained for the PIN 100/0/0 reference sample and EN-Plus requirements.

Size is commonly associated with pellet quality, since shorter pellets are more easily breakable. The length (L) and diameter $(\varnothing)$ of 20 randomly selected pellets were measured for each sample following the procedure described in the literature [38].

Normally, particle density ( $\left.\rho_{\text {particle }}\right)$ is obtained using a stereometric method (mass/volume ratio), by determining the volume of each pellet from its length and diameter, and measuring its mass. The length and mass are measured twice, whilst diameter must be measured six times, twice at each end and twice in the middle.

The BD was determined by measuring the mass of the samples and volume in a $1500 \mathrm{~mL}$ test tube after 300 hits using a tapped density analyzer (Autotap from

Quantachrome Instruments). The energy density of the samples, ๆe, was calculated from HHV and BD.

In addition, temperature programmed combustion profiles (DTG) of the selected formulations were obtained by using a Setaram TAG24 thermogravimetric analyzer. Approximately $5 \mathrm{mg}$ of sample was subjected to a controlled combustion program from room temperature to $900{ }^{\circ} \mathrm{C}$ with a heating rate of $15^{\circ} \mathrm{C} / \mathrm{min}$, using an air flow rate of $50 \mathrm{~mL} / \mathrm{min}$.

\section{Results and discussion}

\subsection{Reference sample - PIN 100/0/0}

A batch of raw pine pellets was produced in the Kahl press and was taken as the sample of reference for comparison purposes. Based on the experience of the research group on woody biomass pelletization in the pilot scale pellet press, a moisture content of 15- 
$16 \%$ was employed [39], which is in the range of the values commonly reported in literature [40]. At these conditions optimum quality raw pine pellets were obtained with a DUR value of $99.1 \%$.

227

\subsection{PINT pelletization}

\subsubsection{Moisture content optimization}

Torrefied wood shows poorer pelletization behavior than raw wood and the pelletization gets worse with the increase in torrefaction conditions, i.e., higher temperature and/or residence time [20]. Hydrophobicity makes the pelletization of torrefied wood highly sensitive to the moisture degree. In this work, the effect of moisture on durability of torrefied pellets was studied for the PINT 100/0/16 sample. Densification at pilot scale was tested for three samples with 3,6 and 9\% moisture contents, and their corresponding DUR values were determined.

With 3\% moisture the mixture was too dry; as a result, the grindability of the torrefied biomass particles was enhanced and a light fine dust was attained by the press rollers action, which cause stucking of the die. A moisture content of $6 \%$ produced good quality pellets with DUR values of over $98 \%$. With $9 \%$ moisture a sort of mud formed in the die, which also caused blockage and prevented pelletization. Therefore, a moisture content of $6 \%$ was selected for the subsequent pelletization experiments.

\subsubsection{Glycerol content optimization}

To reduce friction in the die and enhance the properties lost as a result of the partial decomposition of lignin, different additives have been proposed in the bibliography. As described in the Introduction section, various types of vegetable oils have been used. In this work, glycerol was selected as the additive for torrefied pine pelletization. It was added to PINT samples in percentages of 4, 12, 16, 18, 20 and $30 \mathrm{wt} . \%$; their DUR values are presented in Figure 2a. GLY additions below $12 \mathrm{wt} . \%$ proved to be 
unfeasible for pelletization due to die blockage in the press at temperatures below $35^{\circ} \mathrm{C}$. Thus, the corresponding DUR values are omitted from Figure $2 \mathrm{a}$. According to the results of Figure 2a, the highest DUR values were obtained for 16 and 20 wt.\% GLY addition but, as will be shown later, the PINT 100/0/16 sample presented poor physical properties. Addition of $30 \mathrm{wt} \%$ GLY led to brittle pellets with DUR values below $80 \%$. The best results were achieved with $20 \mathrm{wt} . \%$ GLY addition (sample PINT 100/0/20) with an average durability value of $98 \%$.

\subsection{PINT co-pelletization with solid additives}

Torrefied pine was co-pelletized with two solid additives to enhance its binding properties and reduce the production costs without impoverishing its main properties. In this way, raw pine -PIN- and grape pomace -GP- were used as solid additives in this work. Thus, PIN partially replaced PINT in mass percentages of 25,50 and $75 \%$ in the formulation with 20 wt.\% GLY addition (PINT 100/0/20). GP is a wine industry waste that provided good results when pelletized in a single pellet press, hence it was added in percentages of 10 and $20 \mathrm{wt} . \%$ based on the results achieved in our previous work [24]. The obtained formulations were PINT-PIN 75/25/20, PINT-PIN 50/50/20, PINT-PIN 25/75/20, PINT-GP 90/10/20 and PINT-GP 80/20/20.

As can be observed in Figures $2 \mathrm{~b}$ to $2 \mathrm{f}$, all these blends presented poor DUR values. Just PINT-PIN 25/75/20 and PINT-PIN 50/50/20, with DUR values of 92 and 94\%, respectively, were close to the minimum quality required (97.5\%). Due to the results achieved when PINT was partially replaced by PIN in the samples with 20 wt.\% GLY, further tests were carried out for the PINT-PIN series with various percentages of GLY $(0,10$ and 30 wt.\%), and the obtained results are also shown in Figures $2 \mathrm{~b}$ to $2 \mathrm{f}$. A different behavior was observed between PINT-GP and PINT-PIN mixtures. The first series of samples are unfeasible to be pelletized without the incorporation of GLY in the 
blend. A maximum DUR value of 97.5\% was attained for PINT-GP 90/10/10, with a sharp decrease of DUR for 20 and 30 wt.\% GLY addition in PINT-GP 90/10/- and PINT-GP 80/20/- series. Nonetheless, the presence of 10 wt.\% GP permitted to achieve the DUR quality goals.

PINT-PIN blend series displayed different behavior depending on the percentage of PIN in the blend. At the lowest PIN proportion, PINT-PIN 75/25- series, DUR values below acceptable quality limits were achieved for any GLY content (see Figure 2f). However, PINT-PIN 75/25/0 provided hard pellets $($ DUR $=97.9 \%)$ but suffered the same drawbacks previously noticed for PINT, with die blockage at $35^{\circ} \mathrm{C}$. The blends with high PIN content in their formulations, i.e., PINT-PIN 25/75/- and PINT-PIN 50/50/-, shown in Figures $2 \mathrm{~d}$ and $2 \mathrm{e}$, respectively, presented better durability values, and three samples reached the DUR quality criterion, with values of $98.6,97.5$ and $97.9 \%$ for PINT-PIN 50/50/0, PINT-PIN 50/50/10 and PINT-PIN 25/75/0, respectively. Figure 3 shows images of samples obtained with the selected formulations.

\subsection{Extended analysis for the best formulations}

The experimental procedure was extended to the seven formulations that presented DUR values of over $97.5 \%$. The samples and their durability, moisture and ash contents, $\mathrm{HHV}, \mathrm{BD}, \eta_{\mathrm{e}}$ and physical properties are shown in Table 3 . The values obtained for the reference raw PIN formulation and those required to fulfill residential heating (EN-Plus) [13] and industrial use (ISO 17225-2) [37] quality standards are also included in Table 3.

As can be observed in Table 3 the densification process widely enhances the energy density of the torrefied biomass, $\eta_{e}$, from the original $5.36 \mathrm{GJ} / \mathrm{m}^{3}$ of PINT to values that vary from 11.57 to $15.33 \mathrm{GJ} / \mathrm{m}^{3}$ depending on the formulation. These values are in the region or even higher than that of a dense powdery fuel like GP $\left(12.92 \mathrm{GJ} / \mathrm{m}^{3}\right)$. 
Regarding the presence of GLY, it can be observed in Table 3 that its behavior is very different when considering its addition to PINT or to PINT-GP, PINT-PIN blends. The incorporation of GLY to PINT enhanced BD and thus $\eta_{e}$, with energy density values between $13.98-15.01 \mathrm{GJ} / \mathrm{m}^{3}$, which greatly exceeded the $5.36 \mathrm{GJ} / \mathrm{m}^{3}$ of PINT. PINT 100/0/16 showed promising BD and $\eta_{\mathrm{e}}$ values, although it was considered of slightly lower quality due to the short length of the pellets produced with this formulation which are $10 \mathrm{~mm}$ long on average, as a consequence of the poor lubrication previously mentioned. The sample with 20 wt.\% GLY addition, PINT 100/0/20 offered significant improvement because hard, long and dense pellets were obtained (98\% DUR, $21 \mathrm{~mm}$ length and $1.1 \mathrm{~g} / \mathrm{cm}^{3}$ density on average).

On the other hand, the addition of GLY to PINT-PIN caused a decrease in $\eta_{\mathrm{e}}$ from 12.18 $\mathrm{GJ} / \mathrm{m}^{3}$ of PINT-PIN 50/50/0 to $10.85 \mathrm{GJ} / \mathrm{m}^{3}$ of PINT-PIN 50/50/10, as the HHV enhancement did not compensate the BD decrease caused by GLY addition. The increasing proportion of PIN in the PINT-PIN blends induced a decrease in the bulk density and $\eta_{\mathrm{e}}$ values. Physical properties indicate an adequate homogeneity for all tested PINT-PIN series, with lengths and $\eta_{\text {part }}$ between $18-21 \mathrm{~mm}$ and $1.0-1.2 \mathrm{~g} / \mathrm{cm}^{3}$, respectively. The most noticeable feature regarding physical properties of the PINT-PIN series is the slight diameter widening with the increase of PINT in the blend, raising from 6.0 to $6.2 \mathrm{~mm}$ for PINT-PIN 25/75/0 and PINT-PIN 75/25/0, respectively. Similar increase in the width of the pellets was observed with the addition of GLY in the PINTPIN series. Nevertheless, this increase in diameter is not relevant with regards to the pellets quality. Thus, it can be stated that in the case of PINT-PIN formulations, the addition of GLY did not induce an obvious benefit, because PIN already plays the role of binder and lubricant during the pelletization of PINT. 
323 A completely different behavior was observed with the addition of $10 \mathrm{wt} . \%$ GP to the formulation of PINT with 10 wt.\% GLY (PINT-GP 90/10/10). This sample provided good quality fuels according to the results given in Table 3 . The addition of $10 \mathrm{wt} . \%$ GP contributed to the replacement of the lignin partially lost during torrefaction and decreased the friction in the die, avoiding blockages that were attained with samples with higher GP percentages. As can be observed in Table 3, long (24 mm), dense $\left(1.2 \mathrm{~g} / \mathrm{cm}^{3}\right)$ pellets were obtained under these conditions. PINT-GP 90/10/10 presented the highest energy density $\left(15.33 \mathrm{GJ} / \mathrm{m}^{3}\right)$ of all the tested formulations and this value is $23 \%$ higher than that of the raw PIN pellets. Hence, it could be stated that adding in combination low quantities of GP and GLY could be a good alternative for the improvement in the quality of torrefied pellets.

As can be observed in Table 3, two of the proposed formulations slightly exceeded the maximum required moisture content $(\leq 10 \%)$ and displayed the lowest $\eta_{\mathrm{e}}$ of the series, temperature programmed combustion tests or DTG profiles as described in Section 2.2 and the results are represented in Figure 4. The combustion profile obtained for PIN $100 / 0 / 0$ is also provided in the same figure for comparison purposes. 
In all the cases a peak can be noticed close to $70^{\circ} \mathrm{C}$ that indicates the loss of moisture.

349 For the raw pine sample, PIN 100/0/0 two ulterior peaks were observed, the main one occurred at $333{ }^{\circ} \mathrm{C}$ and corresponds to the loss of volatiles, while the peak appearing at $466^{\circ} \mathrm{C}$ is due to the combustion of the solid char. The samples with GLY in their composition (PINT 100/0/20 and PINT-GP 90/10/10) presented another peak at a temperature close to $188^{\circ} \mathrm{C}$, characteristic of the volatilization of GLY. Besides, in these two samples the volatiles peak, and especially the chars peak, appear earlier than in the samples without GLY and/or GP in their composition. It could infer that the presence of GLY and GP increases the reactivity of the mixtures. This aspect was also observed in previous works [41] and reinforces the idea that reactivity is enhanced by small amounts of GLY and/or GP.

\subsection{Economic analysis}

Finally, a brief balance was undertaken to analyze the economics behind the production benchmarking. The first aspect to be taken into account was the Production Cost (PC, in $€ /$ ton) which was obtained as a sum of the feedstock (raw pine) and additives (GP, GLY) cost, the pretreatment cost (grinding and torrefaction) and the pelletization cost, estimated from the energy consumption measured in the pelletizer. The estimated values are detailed in Table 4.

$$
\mathrm{PC}=\text { Feedstock }+ \text { Additives }+ \text { Pretreatment }+ \text { Pelletization }
$$

Properties like HHV, BD and $\eta_{\mathrm{e}}$ were used to estimate the Energy Cost or price per $\mathrm{kJ}$ obtained from each $\mathrm{kg}$ of sample $(\mathrm{EC}$, in $€ / \mathrm{kJ})$ and the Net Energy Cost $(\mathrm{NEC}$, in $€ / \mathrm{kJ})$, that excludes moisture and ash from the calculation:

$$
\begin{gathered}
E C=\frac{P C}{H H V} \\
N E C=\frac{P C}{H H V \cdot(1-(A+M))}
\end{gathered}
$$


373 Where $H H V, A, M$ and $B D$ are respectively the higher heating value $(\mathrm{kJ} / \mathrm{kg})$, ash content

374 (wt.\%, db), moisture content (wt.\%, as received) and bulk density $\left(\mathrm{kg} / \mathrm{m}^{3}\right)$ of each considered formulation.

In addition, the Transport (TC, in $€ / \mathrm{kWh} \cdot \mathrm{km})[42]$ and Store construction (SC, in $€)$

377 Costs, which are widely influenced by the physical properties of the biomass, were also

378 calculated. To this aim the most common commercial truck used in Spain $\left(24 \mathrm{t} / 80 \mathrm{~m}^{3}\right)$ and its price per kilometer $(1.160 € / \mathrm{km})[43]$ were considered as reference:

$$
T C=\frac{1.160}{80 \cdot B D \cdot H H V} \cdot 3.6 \cdot 10^{6}
$$

In order to determine the Store onstruction Cost, SC, it was necessary to determine the constructive costs [44] of a concrete silo $\left(\mathrm{SV}, \mathrm{in}^{3}\right)$ required to feed a reference boiler [33]:

$$
S V=\frac{P \cdot t}{H H V \cdot B D} \cdot 3600
$$

Where $P$ and $t$ are the reference boiler power $(\mathrm{kW})$ and the designed storage time, measured in days, respectively.

The relative costs for each sample were compared with the cost of PIN 100/0/0 and the obtained results are summarized in Figure 5. As can be observed the PC, EC and NEC of the proposed formulations were more expensive than the costs obtained for PIN. This was expected because the samples require treatments and/or additives that increase the cost. Despite GP being cheaper than PIN, the addition of just $10 \%$ implied a negligible cost reduction.

The costs especially affected by the quality parameters, HHV and BD, indicated that some of the tested formulations, PINT 100/0/20 and PINT-GP 90/10/10, are economically competitive with PIN 100/0/0, with savings of approximately 10 to $20 \%$ in constructive and transport costs. As these costs are relative, longer distances of transport and bigger volumes of the silo will deliver higher savings, which makes these 
formulations especially interesting for large installations (i.e., combined heat and power

399

400

401

402

403

404

405

406

407

408

409

410

411

412

413

414

415

416

417

418

419

420

421

422 plants, district heating systems or industrial power plants) where big amounts of fuel are delivered far away from the production facilities. Values calculated for the buried silo varied between 200 and $2300 €$ for installations of $25 \mathrm{~kW}$ and $1 \mathrm{MW}$, respectively, in agreement with Chai and Saffron [45]. The determined costs of transport varied between 215 and $280 €$ per trip to transport the same amount of energy a distance of $1000 \mathrm{~km}$. These data indicate that the utilization of high quality pellets is beneficial and can be particularly competitive for big installations located far from the production point [46].

Although the production of torrefied biomass pellets is undeniably more expensive than the pelletization of raw biomass, it enhances the properties of the pellets and points out towards alternative future uses. Small or medium-size domestic boilers are particularly suitable for raw biomass pellets. Furthermore, there are applications, even different from purely power production, that require long term storage or large distance transportation, where the enhanced properties of torrefied biomass pellets (high energy density, hydrophobicity or increased grindability) deliver added value that can compensate its increased production cost. Among the non-power generation industries where torrefied biomass pellets can encounter potential application and that are energy-intensive one can cite the iron and steel industry, the chemical and petrochemical industry, the paper, pulp and printing industry and non-metallic minerals (glass, ceramic, cement, etc.) [47].

\section{Conclusions}

The pelletization of torrefied pine, PINT, was studied at low temperature in a benchscale continuous pellet press. The effect of moisture and additives such as pine (PIN), grape pomace (GP) and glycerol (GLY) on the main characteristics of the obtained 
pellets were evaluated and compared with pellets produced from raw pine and international standard requirements. Torrefied biomass pelletization was highly sensitive to moisture and lubricant contents. Blends of PIN or GP and/or GLY with PINT provided four formulations with durability, DUR, and energy density values, $\eta_{\mathrm{e}}$, higher than $97.5 \%$ and $12 \mathrm{GJ} / \mathrm{m}^{3}$, respectively, as well as quite homogeneous physical properties. Of special interest were the formulations of torrefied pine with $20 \mathrm{wt} . \%$ glycerol (PINT 100/0/20) and that of torrefied pine with $10 \mathrm{wt} . \%$ grape pomace and 10 wt.\% glycerol (PINT-GP 90/10/10). These blends resulted in hard, dense pellets with $\eta_{\mathrm{e}}$ values of 13.98 and $15.33 \mathrm{GJ} / \mathrm{m}^{3}$, which were $12 \%$ and $23 \%$ higher than that of raw pine pellets, respectively. All the selected formulations present properties that accomplish both EN-Plus and ISO 17225-2-Industrial Pellets Quality standards, making them suitable for a wider range of uses, such as residential heating systems and power plant boilers. Moreover, the formulations PINT 100/0/20 and PINT-GP 90/10/10 are economically competitive to traditional raw PIN pellets, especially for uses such as cofiring with coal, big installations, long storage times or long-distance delivery, where enhanced grindability properties, hydrophobicity or high energy density are required. The use of low-added-value by-products such as GP, as pelletization additives in this work, has proven to be of utmost interest as they present undeniable economic advantages when compared to the feedstocks traditionally used to this end.

\section{Acknowledgements}

443 This work was supported by the Spanish MINECO (ENE2014-53515-P) and by the 444 Gobierno del Principado de Asturias (PCTI, Ref. IDI/2018/000115), both with co445 funding from the European Regional Development Fund (ERDF). M.P.G-V. also acknowledges a fellowship awarded by the Spanish MINECO (FPI program), cofinanced by the European Social Fund. 
449 [1] British Petroleum, BP Statistical Review of World Energy 2018, 2018.

H. Lu, W. Robert, G. Peirce, B. Ripa, L.L. Baxter, Comprehensive study of biomass particle combustion, Energy and Fuels. 22 (2008) 2826-2839. doi:10.1021/ef800006z.

[3] A. Demirbas, Importance of biomass energy sources for Turkey, Energy Policy. 36 (2008) 834-842. doi:10.1016/j.enpol.2007.11.005.

[4] A. Pimchuai, A. Dutta, P. Basu, Torrefaction of agriculture residue to enhance combustible properties, Energy and Fuels. 24 (2010) 4638-4645. doi:10.1021/ef901168f.

[5] H. Zhou, Y. Li, N. Li, R. Qiu, K. Cen, NO and N2O Emissions during Devolatilization and Char Combustion of a Single Biomass Particle under Oxyfuel Conditions at Fluidized Bed Temperature, Energy and Fuels. 31 (2017) 7157-7165. doi:10.1021/acs.energyfuels.7b00798.

[6] L. Kumar, A.A. Koukoulas, S. Mani, J. Satyavolu, Integrating torrefaction in the wood pellet industry: A critical review, Energy and Fuels. 31 (2017) 37-54. doi:10.1021/acs.energyfuels.6b02803.

[7] J.K. Holm, W. Stelte, D. Posselt, J. Ahrenfeldt, U.B. Henriksen, Optimization of a multiparameter model for biomass pelletization to investigate temperature dependence and to facilitate fast testing of pelletization behavior, Energy and Fuels. 25 (2011) 3706-3711. doi:10.1021/ef2005628.

[8] M. Puig-Arnavat, J. Ahrenfeldt, U.B. Henriksen, Validation of a Multiparameter Model to Investigate Torrefied Biomass Pelletization Behavior, Energy and Fuels. 31 (2017) 1644-1649. doi:10.1021/acs.energyfuels.6b02895.

[9] S.B. Saleh, B.B. Hansen, P.A. Jensen, K. Dam-Johansen, Influence of biomass 
chemical properties on torrefaction characteristics, Energy and Fuels. 27 (2013) 7541-7548. doi:10.1021/ef401788m.

[10] B. Arias, C. Pevida, J. Fermoso, M.G. Plaza, F. Rubiera, J.J. Pis, Influence of torrefaction on the grindability and reactivity of woody biomass, Fuel Process. Technol. 89 (2008) 169-175. doi:10.1016/j.fuproc.2007.09.002.

[11] T. Keipi, H. Tolvanen, L. Kokko, R. Raiko, The effect of torrefaction on the chlorine content and heating value of eight woody biomass samples, Biomass and Bioenergy. 66 (2014) 232-239. doi:10.1016/j.biombioe.2014.02.015.

[12] B. Batidzirai, A.P.R. Mignot, W.B. Schakel, H.M. Junginger, A.P.C. Faaij, Biomass torrefaction technology: Techno-economic status and future prospects, Energy. 62 (2013) 196-214. doi:10.1016/j.energy.2013.09.035.

[13] EPC-European Pellet Council, EN-Plus handbook part 3: Pellets quality requirements, 2015.

[14] C. Verhoest, Y. Ryckmans, Industrial Wood Pellets Report, 2012.

[15] R. García, M. Gil, M. González-Vázquez, F. Rubiera, C. Pevida, Biomass Pelletization: Contribution to Renewable Power Generation Scenarios, in: Z. Fang, R. Smith, J. Tian (Eds.), Prod. Mater. from Sustain. Biomass Resour., Springer, Singapore, 2019: pp. 269-294. doi:10.1007/978-981-13-3768-0.

[16] L. Shang, N.P.K. Nielsen, W. Stelte, J. Dahl, J. Ahrenfeldt, J.K. Holm, M.P. Arnavat, L.S. Bach, U.B. Henriksen, Lab and Bench-Scale Pelletization of Torrefied Wood Chips-Process Optimization and Pellet Quality, Bioenergy Res. 7 (2014) 87-94. doi:10.1007/s12155-013-9354-z.

[17] L. Cao, X. Yuan, H. Li, C. Li, Z. Xiao, L. Jiang, B. Huang, Z. Xiao, X. Chen, H. Wang, G. Zeng, Complementary effects of torrefaction and co-pelletization: Energy consumption and characteristics of pellets, Bioresour. Technol. 185 
(2015) 254-262. doi:10.1016/j.biortech.2015.02.045.

[18] A. Abedi, A.K. Dalai, Study on the quality of oat hull fuel pellets using bioadditives, Biomass and Bioenergy. 106 (2017) 166-175. doi:10.1016/j.biombioe.2017.08.024.

[19] J. Peng, X.T. Bi, C.J. Lim, H. Peng, C.S. Kim, D. Jia, H. Zuo, Sawdust as an effective binder for making torrefied pellets, Appl. Energy. 157 (2014) 491-498. doi:10.1016/j.apenergy.2015.06.024.

[20] M.T. Reza, M.H. Uddin, J.G. Lynam, C.J. Coronella, Engineered pellets from dry torrefied and HTC biochar blends, Biomass and Bioenergy. 63 (2014) 229-238. doi:10.1016/j.biombioe.2014.01.038.

[21] A. Pirraglia, R. Gonzalez, D. Saloni, J. Wright, J. Denig, Fuel properties and suitability of Eucalyptus benthamii and Eucalyptus macarthurii for torrefied wood and pellets, BioResources. 7 (2012) 217-235. doi:10.15376/biores.7.1.0217-0235.

[22] L.E. Arteaga-Pérez, H. Grandón, M. Flores, C. Segura, S.S. Kelley, Steam torrefaction of Eucalyptus globulus for producing black pellets: A pilot-scale experience, Bioresour. Technol. 238 (2017) 194-204. doi:10.1016/j.biortech.2017.04.037.

[23] M. Rudolfsson, S.H. Larsson, T.A. Lestander, New tool for improved control of sub-process interactions in rotating ring die pelletizing of torrefied biomass, Appl. Energy. 190 (2017) 835-840. doi:10.1016/j.apenergy.2016.12.107.

[24] R. García, M.P. González-Vázquez, C. Pevida, F. Rubiera, Pelletization properties of raw and torrefied pine sawdust: Effect of co-pelletization, temperature, moisture content and glycerol addition, Fuel. 215 (2018) 290-297. doi:10.1016/j.fuel.2017.11.027. 
[25] A. Álvarez, C. Pizarro, R. García, J.L. Bueno, Spanish biofuels heating value estimation based on structural analysis, Ind. Crops Prod. 77 (2015) 983-991. doi:10.1016/j.indcrop.2015.09.078.

[26] C. Sakkampang, T. Wongwuttanasatian, Study of ratio of energy consumption and gained energy during briquetting process for glycerin-biomass briquette fuel, Fuel. 115 (2014) 186-189. doi:10.1016/j.fuel.2013.07.023.

[27] S. Emami, L.G. Tabil, P. Adapa, Effect of glycerol on densification of agricultural biomass, Int. J. Agric. Biol. Eng. 8 (2015) 64-73. doi:10.3965/j.ijabe.20150801.009.

[28] P. Bartocci, A. Anca-Couce, K. Slopiecka, S. Nefkens, N. Evic, S. Retschitzegger, M. Barbanera, C. Buratti, F. Cotana, G. Bidini, F. Fantozzi, Pyrolysis of pellets made with biomass and glycerol: Kinetic analysis and evolved gas analysis, Biomass and Bioenergy. 97 (2017) 11-19. doi:10.1016/j.biombioe.2016.12.004.

[29] L. Raslavičius, Characterization of the woody cutting waste briquettes containing absorbed glycerol, Biomass and Bioenergy. 45 (2012) 144-151. doi:10.1016/j.biombioe.2012.05.028.

[30] P. Bartocci, G. Bidini, F. Asdrubali, C. Beatrice, F. Frusteri, F. Fantozzi, Batch pyrolysis of pellet made of biomass and crude glycerol: Mass and energy balances, Renew. Energy. (2017). doi:10.1016/j.renene.2017.06.049.

[31] M. V. Gil, R. García, C. Pevida, F. Rubiera, Grindability and combustion behavior of coal and torrefied biomass blends, Bioresour. Technol. 191 (2015) 205-212. doi:10.1016/j.biortech.2015.04.117.

[32] M. V. Gil, P. Oulego, M.D. Casal, C. Pevida, J.J. Pis, F. Rubiera, Mechanical durability and combustion characteristics of pellets from biomass blends, 
Bioresour. Technol. 101 (2010) 8859-8867. doi:10.1016/j.biortech.2010.06.062.

549

550

551

552

553

554

555

556

557

558

559

560

561

562

563

564

565

566

567

568

569

570

571

572

[33] R. García Fernández, C. Pizarro García, A. Gutiérrez Lavín, J.L. Bueno de las Heras, J.J. Pis, Influence of physical properties of solid biomass fuels on the design and cost of storage installations, Waste Manag. 33 (2013) 1151-1157. doi:10.1016/j.wasman.2013.01.033.

[34] P.K. Adapa, G.J. Schoenau, L.G. Tabil, E.A. Arinze, A.K. Singh, A.K. Dalai, Customized and Value-added High Quality Alfalfa Products : A New Concept, Agric. Eng. Int. CIGR Ejournal. IX (2007) 1-28.

[35] S.R. Richards, Physical Testing of Fuel Briquettes, Fuel Process Technol. 25 (1990) 89-100.

[36] European Pellet Council, Manual ENPlus. Esquema de certificación de calidad para pellets de madera, 2016 .

[37] ISO, ISO 17225-2:2014. Solid biofuels, Fuel specifications and classes, Part 2: Graded wood pellets, 2014.

[38] M.T. Carone, A. Pantaleo, A. Pellerano, Influence of process parameters and biomass characteristics on the durability of pellets from the pruning residues of Olea europaea L, Biomass Bioenerg. 35 (2011) 402-410. doi:10.1016/j.biombioe.2010.08.052.

[39] R. García, M. V. Gil, F. Rubiera, C. Pevida, Pelletization of wood and alternative residual biomass blends for producing industrial quality pellets, Fuel. 251 (2019) 739-753. doi:10.1016/j.fuel.2019.03.141.

[40] S.H. Larsson, M. Rudolfsson, Temperature control in energy grass pellet production - Effects on process stability and pellet quality, Appl. Energy. 97 (2012) 24-29. doi:10.1016/j.apenergy.2011.11.086.

[41] M.P. González-Vázquez, R. García, C. Pevida, F. Rubiera, Optimization of a 
bubbling fluidized bed plant for low-temperature gasification of biomass, Energies. 10 (2017). doi:10.3390/en10030306.

[42] R. García, C. Pizarro, A.G. Lavín, J.L. Bueno, Biomass sources for thermal conversion. Techno-economical overview, Fuel. 195 (2017) 182-189. doi:10.1016/j.fuel.2017.01.063.

[43] Ministerio de Fomento, Observatorio de costes del transporte de mercancías por carretera, 2016.

[44] S.A. CYPE Ingenieros, Generador de precios. España, (2017). http://www.generadordeprecios.info/.

[45] L. Chai, C.M. Saffron, Comparing pelletization and torrefaction depots: Optimization of depot capacity and biomass moisture to determine the minimum production cost, Appl. Energy. 163 (2016) 387-395. doi:10.1016/j.apenergy.2015.11.018.

[46] D.A. Agar, A comparative economic analysis of torrefied pellet production based on state-of-the-art pellets, Biomass and Bioenergy. 97 (2017) 155-161. doi:10.1016/j.biombioe.2016.12.019.

[47] S. Proskurina, J. Heinimö, F. Schipfer, E. Vakkilainen, Biomass for industrial applications: The role of torrefaction, Renew. Energy. 111 (2017) 265-274. doi:10.1016/j.renene.2017.04.015. 
594 Table 1. Ultimate and proximate analyses, high heating value, bulk density and energy density of the samples used in this work.

\begin{tabular}{|c|c|c|c|c|c|c|c|c|c|c|c|c|}
\hline & \multicolumn{5}{|c|}{ Ultimate analysis (wt.\%, db) } & \multicolumn{4}{|c|}{ Proximate analysis (wt.\%) } & \multirow{2}{*}{$\begin{array}{c}\mathrm{HHV}_{\mathrm{ar}} \\
(\mathrm{MJ} / \mathrm{kg})\end{array}$} & \multirow{2}{*}{$\begin{array}{c}\text { BD } \\
\left(\mathbf{k g} / \mathbf{m}^{3}\right)\end{array}$} & \multirow{2}{*}{$\begin{array}{c}\eta_{\mathrm{e}} \\
\left(\mathbf{G J} / \mathbf{m}^{3}\right)\end{array}$} \\
\hline & $\begin{array}{ll}\mathbf{C} \\
\end{array}$ & $\mathbf{N}$ & H & $\mathbf{S}$ & $\mathbf{O}$ & $\mathbf{M}^{\mathrm{ar}}$ & Ash $^{\mathrm{db}}$ & $\mathbf{V M}^{\mathrm{db}}$ & $\mathbf{F C}^{\mathrm{db}}$ & & & \\
\hline GLY & 39.1 & - & 8.7 & - & 52.2 & - & - & - & - & 17.9 & $1261 *$ & \\
\hline GP & 45.5 & 1.8 & 5.1 & 0.2 & 34.7 & 11.6 & 12.7 & 67.6 & 19.7 & 16.7 & 772 & 12.92 \\
\hline PIN & 51.0 & 0.3 & 6.0 & 0.0 & 42.3 & 9.6 & 0.4 & 85.1 & 14.5 & 18.2 & 226 & 4.10 \\
\hline PINT & 55.9 & 0.2 & 5.7 & 0.0 & 37.5 & 8.8 & 0.7 & 78.4 & 20.9 & 20.2 & 265 & 5.36 \\
\hline
\end{tabular}

596 db: dry basis; ar: as received. $\mathrm{M}^{\text {ar: }}$ indicates the moisture ar at which $\mathrm{HHV}$ is

597 determined; VM: volatile matter; FC: fixed carbon; BD: bulk density.

$598 *$ This value indicates density.

599 
Table 2. Detailed blend composition in wt.\% of each component.

\begin{tabular}{|c|c|c|c|c|}
\hline Sample & PINT $^{*}$ & PIN* & GP* $^{*}$ & GLY $^{* *}$ \\
\hline \multicolumn{5}{|c|}{ Reference sample } \\
\hline PIN 100/0/0 & 0 & 100 & 0 & 0 \\
\hline \multicolumn{5}{|c|}{ PINT Pelletization } \\
\hline PINT 100/0/4 & 100 & 0 & 0 & 4 \\
\hline PINT 100/0/12 & 100 & 0 & 0 & 12 \\
\hline PINT 100/0/16 & 100 & 0 & 0 & 16 \\
\hline PINT 100/0/18 & 100 & 0 & 0 & 18 \\
\hline PINT 100/0/20 & 100 & 0 & 0 & 20 \\
\hline PINT 100/0/30 & 100 & 0 & 0 & 30 \\
\hline \multicolumn{5}{|c|}{ PINT-GP Co-pelletization } \\
\hline PINT-GP 90/10/0 & 90 & 0 & 10 & 0 \\
\hline PINT-GP 90/10/10 & 90 & 0 & 10 & 10 \\
\hline PINT-GP 90/10/20 & 90 & 0 & 10 & 20 \\
\hline PINT-GP 90/10/30 & 90 & 0 & 10 & 30 \\
\hline PINT-GP 80/20/0 & 80 & 0 & 20 & 0 \\
\hline PINT-GP 80/20/10 & 80 & 0 & 20 & 10 \\
\hline PINT-GP 80/20/20 & 80 & 0 & 20 & 20 \\
\hline PINT-GP 80/20/30 & 80 & 0 & 20 & 30 \\
\hline \multicolumn{5}{|c|}{ PINT-PIN Co-pelletization } \\
\hline PINT-PIN 25/75/0 & 25 & 75 & 0 & 0 \\
\hline PINT-PIN 25/75/10 & 25 & 75 & 0 & 10 \\
\hline PINT-PIN 25/75/20 & 25 & 75 & 0 & 20 \\
\hline PINT-PIN 50/50/0 & 50 & 50 & 0 & 0 \\
\hline PINT-PIN 50/50/10 & 50 & 50 & 0 & 10 \\
\hline PINT-PIN 50/50/20 & 50 & 50 & 0 & 20 \\
\hline PINT-PIN 75/25/0 & 75 & 25 & 0 & 0 \\
\hline PINT-PIN 75/25/10 & 75 & 25 & 0 & 10 \\
\hline PINT-PIN 75/25/20 & 75 & 25 & 0 & 20 \\
\hline
\end{tabular}

$601 *$ Component quantity in mass percentage

$602 * *$ Amount of glycerol added to the blend in mass percentage of the overall solid

603 components quantity.

604 
Table 3. Physical properties and energy density obtained for the selected pellets.

\begin{tabular}{|c|c|c|c|c|c|c|c|c|c|c|}
\hline Sample & $\begin{array}{c}\text { DUR } \\
(\%)\end{array}$ & $\begin{array}{l}M^{*} \\
(\%)\end{array}$ & $\begin{array}{c}\text { Ash } \\
(\text { wt.\%, db) }\end{array}$ & $\begin{array}{l}\mathbf{H H V}_{\text {wb }} \\
(\mathrm{MJ} / \mathrm{kg})\end{array}$ & $\begin{array}{c}\text { BD } \\
\left(\mathrm{kg} / \mathrm{m}^{3}\right)\end{array}$ & $\begin{array}{c}\mathbf{L} \\
(\mathbf{m m})\end{array}$ & $\begin{array}{c}\varnothing \\
(\mathbf{m m})\end{array}$ & $\begin{array}{c}\text { Ppart } \\
\left(\mathrm{g} / \mathrm{cm}^{3}\right)\end{array}$ & $\begin{array}{c}\eta_{\mathrm{e}} \\
\left(\mathbf{G J} / \mathbf{m}^{3}\right)\end{array}$ & $\begin{array}{c}\text { EN-Plus } \\
\text { Quality }\end{array}$ \\
\hline EN-Plus & $\geq 97.5-98 * *$ & $\leq 10$ & $\leq 0.7-2 * *$ & $\geq 16.5$ & $600-750$ & $3.15-45$ & $6-8( \pm 1)$ & - & - & \\
\hline ISO $17225-2$ & $\geq 96.5-97.5 * *$ & $\leq 10$ & $\leq 1-3 * *$ & $\geq 16.5$ & $\geq 600$ & $3.15-40$ & $6-12( \pm 1)^{* *}$ & - & - & \\
\hline PIN 100/0/0 & 99.1 & 9.98 & 0.3 & 18.4 & 677 & 21 & 6.2 & 1.1 & 12.48 & A1 \\
\hline PINT 100/0/16 & 97.8 & 4.88 & 0.4 & 20.1 & 747 & 10 & 6.2 & 1.1 & 15.01 & A2 \\
\hline PINT 100/0/20 & 98.0 & 3.15 & 0.4 & 20.0 & 698 & 21 & 6.2 & 1.1 & 13.98 & A1 \\
\hline PINT-GP 90/10/10 & 97.5 & 2.59 & 1.87 & 21.7 & 707 & 24 & 6.1 & 1.2 & 15.33 & $\mathrm{~B}$ \\
\hline PINT-PIN 25/75/0 & 97.9 & 10.07 & 0.38 & 19.1 & 605 & 18 & 6.0 & 1.1 & 11.57 & - \\
\hline PINT-PIN 50/50/0 & 98.6 & 7.47 & 0.35 & 19.4 & 629 & 21 & 6.1 & 1.1 & 12.18 & A1 \\
\hline PINT-PIN 50/50/10 & 97.5 & 10.54 & 0.35 & 21.5 & 558 & 17 & 6.4 & 1.0 & 10.85 & - \\
\hline PINT-PIN 75/25/0 & 97.9 & 9.4 & 0.33 & 18.8 & 678 & 20 & 6.2 & 1.2 & 12.74 & $\mathrm{~A} 2$ \\
\hline
\end{tabular}

db: dry basis; wb: wet basis; *Moisture content measured in the obtained pellets and used to correct the HHV $\mathrm{V}_{\mathrm{wb}}$;* Value depending on the pellet quality class A1, A2, B (EN-Plus); I1, I2 or I3 (Industrial Quality Pellets -ISO 17225-2-). EN-Plus Quality indicates the most restrictive quality standard fulfilled by each formulation. 
Table 4. Breakdown of production costs $(€ / t)$ for the selected formulations.

\begin{tabular}{|c|c|c|c|c|c|}
\hline Formulation & Feedstock & Additives & Pretreatment & Pelletization & Total \\
\hline PIN 100/0/0 & 110 & 0 & 4.6 & 27.9 & 142.5 \\
\hline PINT 100/0/20 & 110 & 70 & 6.2 & 51.5 & 237.7 \\
\hline PINT/GP 90/10/10 & 99 & 42.5 & 6.4 & 76.3 & 224.2 \\
\hline PINT/PIN 50/50/0 & 110 & 0 & 5.5 & 39.7 & 155.2 \\
\hline PINT/PIN 75/25/0 & 110 & 0 & 6.4 & 45.6 & 162.0 \\
\hline
\end{tabular}




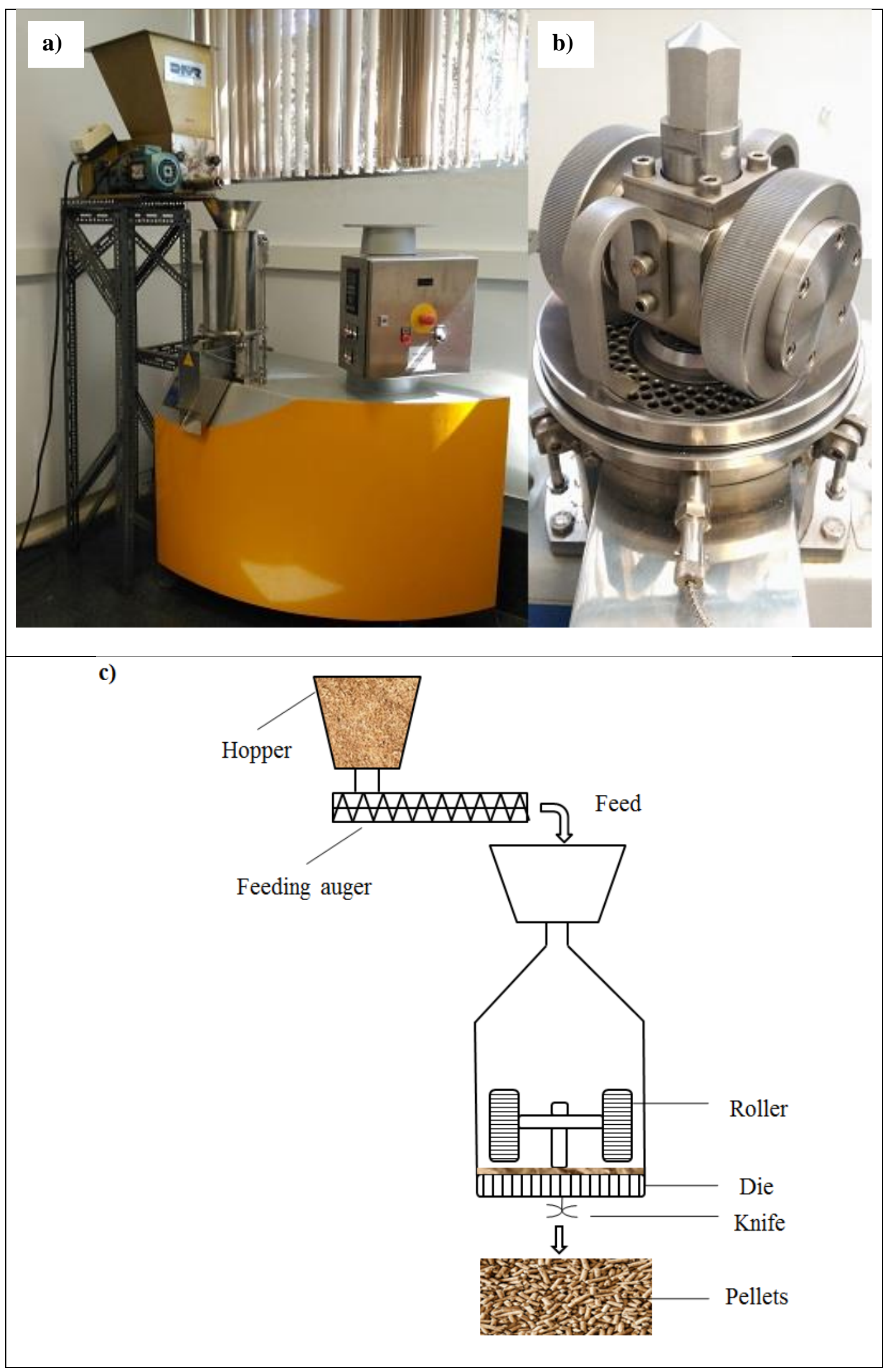

Figure 1. a) Pelletization pilot plant, b) rollers and die and c) pelletizer scheme. 
a) PINT 100/0/- Series

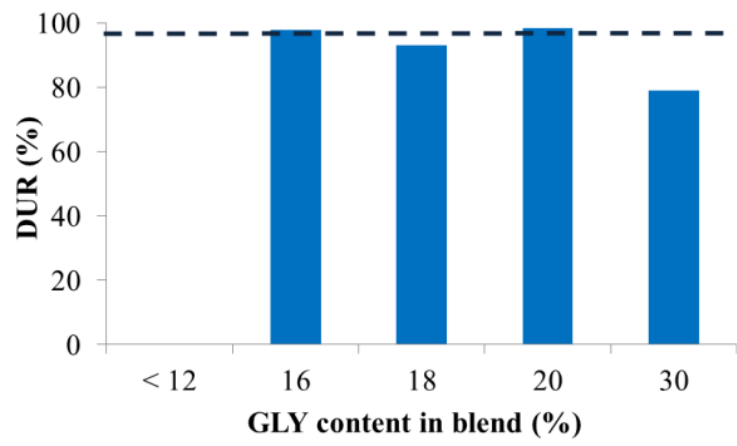

c) PINT-GP 80/20/- Series

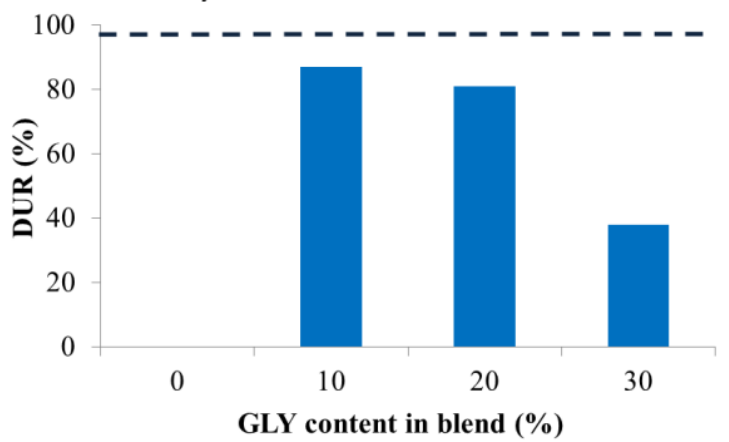

e) PINT-PIN 50/50/- Series

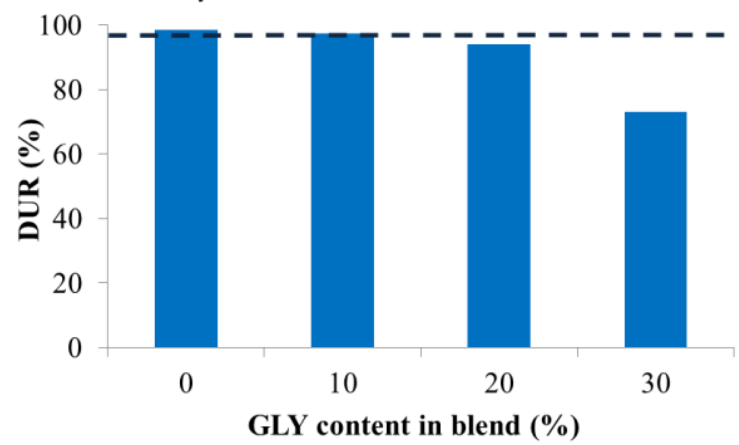

b) PINT-GP 90/10/- Series

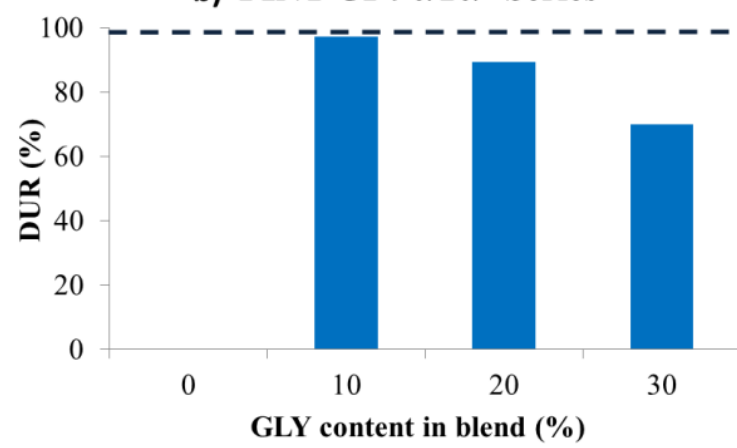

d) PINT-PIN 25/75/- Series

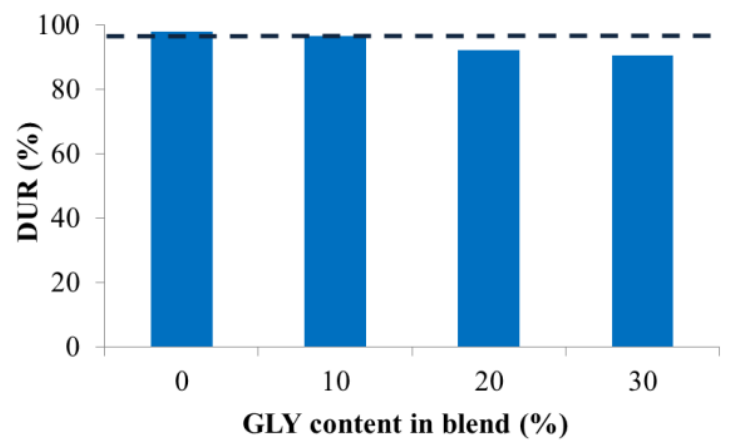

f) PINT-PIN 75/25/- Series

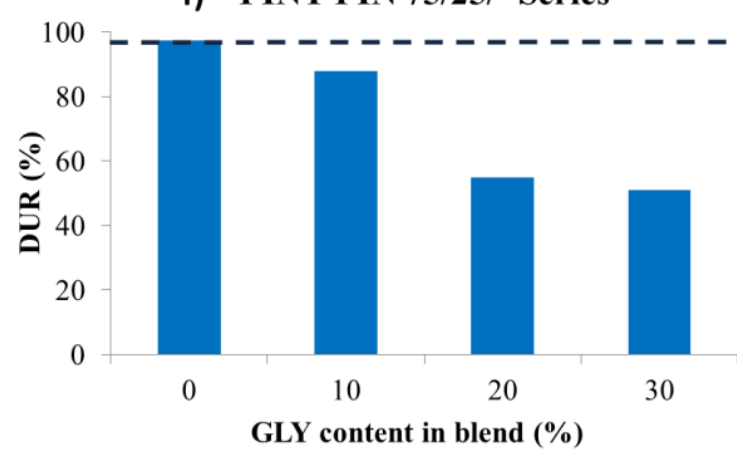

Figure 2. Durability results (\%) for the pelletization of the PINT series. Threshold of durability according to EN-Plus A2 (97.5\%) is represented with a blue dotted line. 

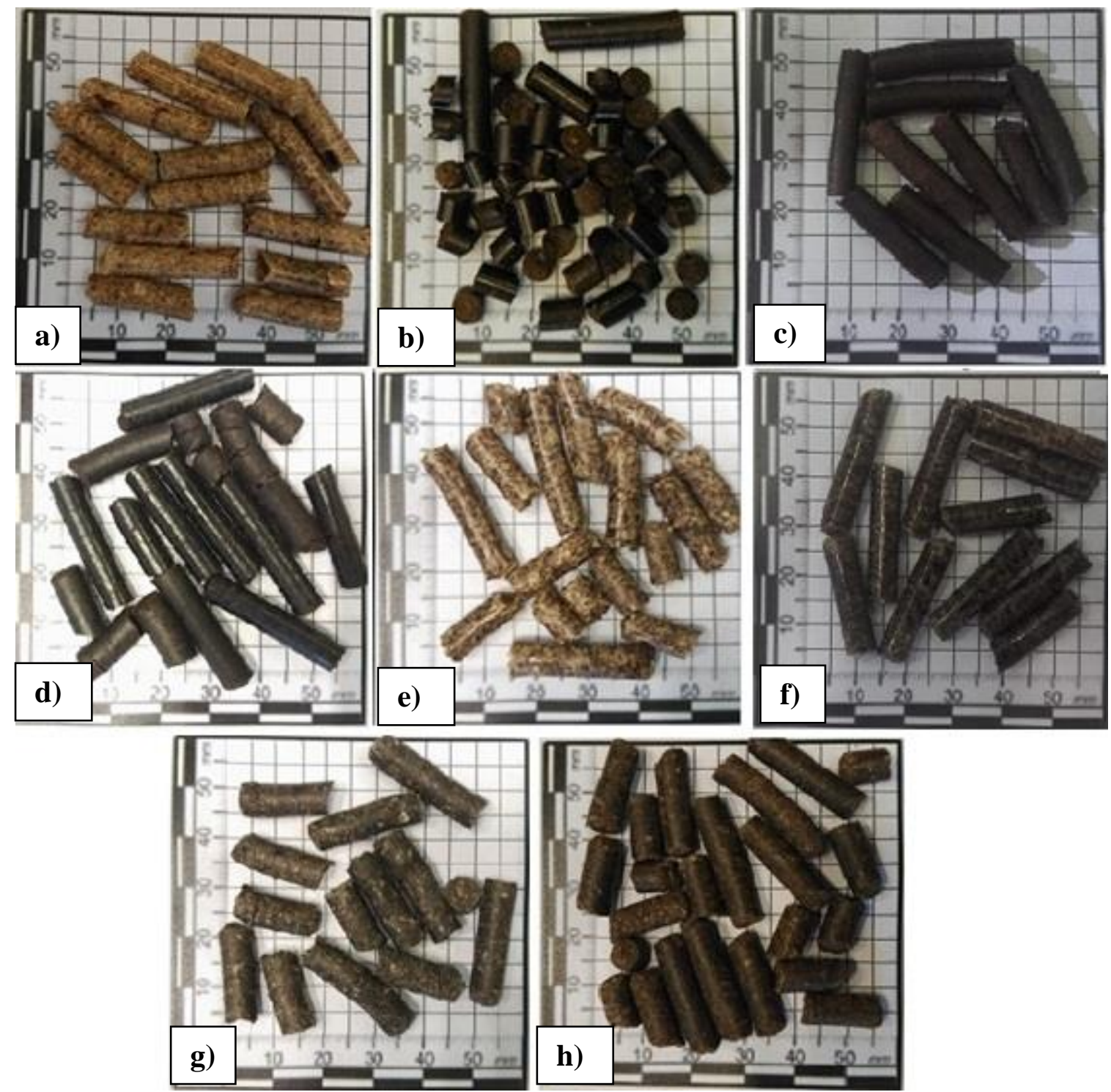

Figure 3. Photographs of the pellets obtained with formulations that presented adequate durability values. a) PIN 100/0/0, b) PINT 100/0/16, c) PINT 100/0/20, d) PINT-GP 90/10/10, e) PINT-PIN 25/75/0, f) PINT-PIN 50/50/0, g) PINT-PIN 50/50/10 and h) PINT-PIN 75/25/0. 


\section{Temperature $\left({ }^{\circ} \mathrm{C}\right)$}

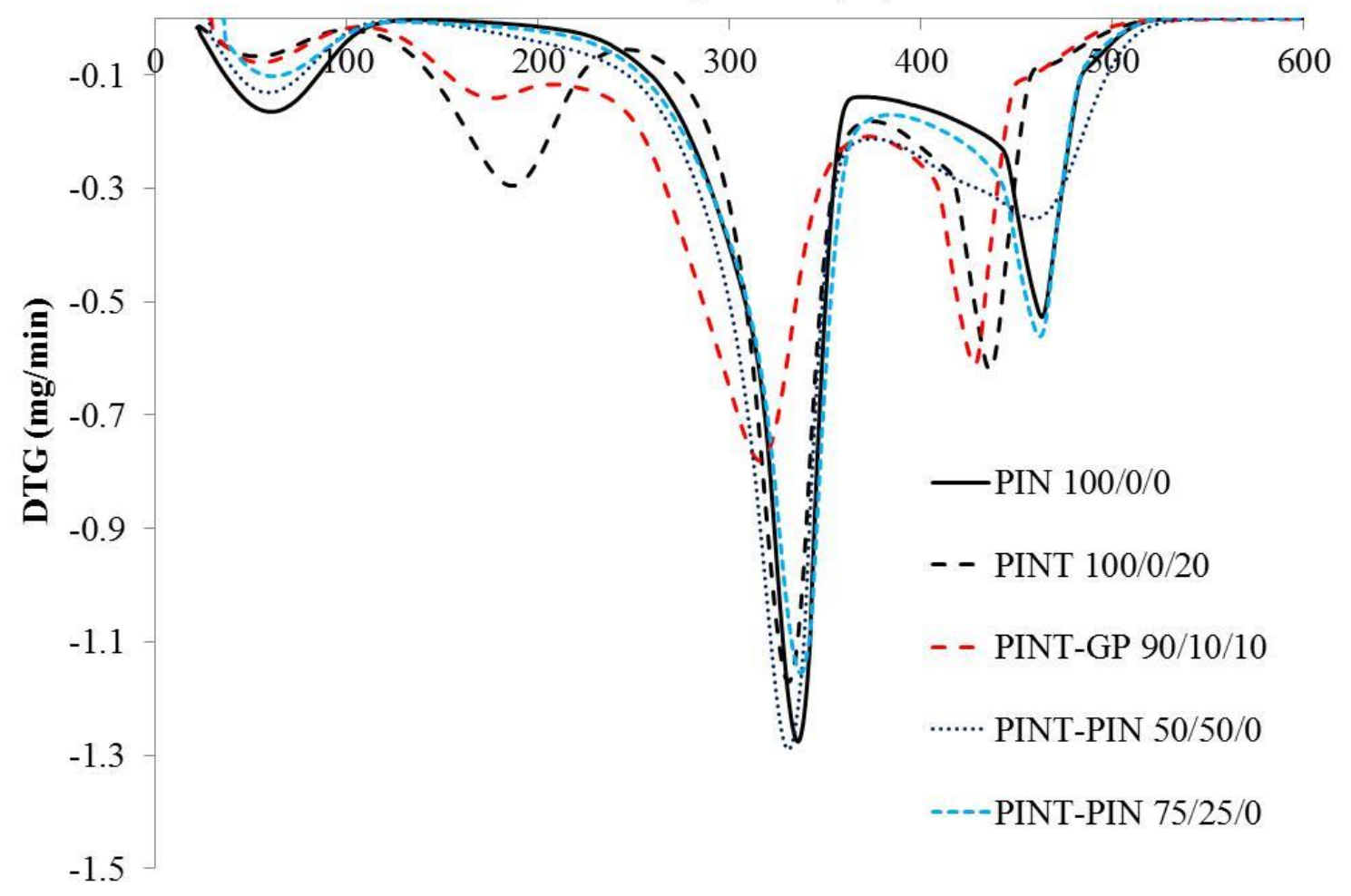

Figure 4. DTG combustion profiles of the selected formulations. (For interpretation of the references to colour in this figure legend, the reader is referred to the web version of this article.) 


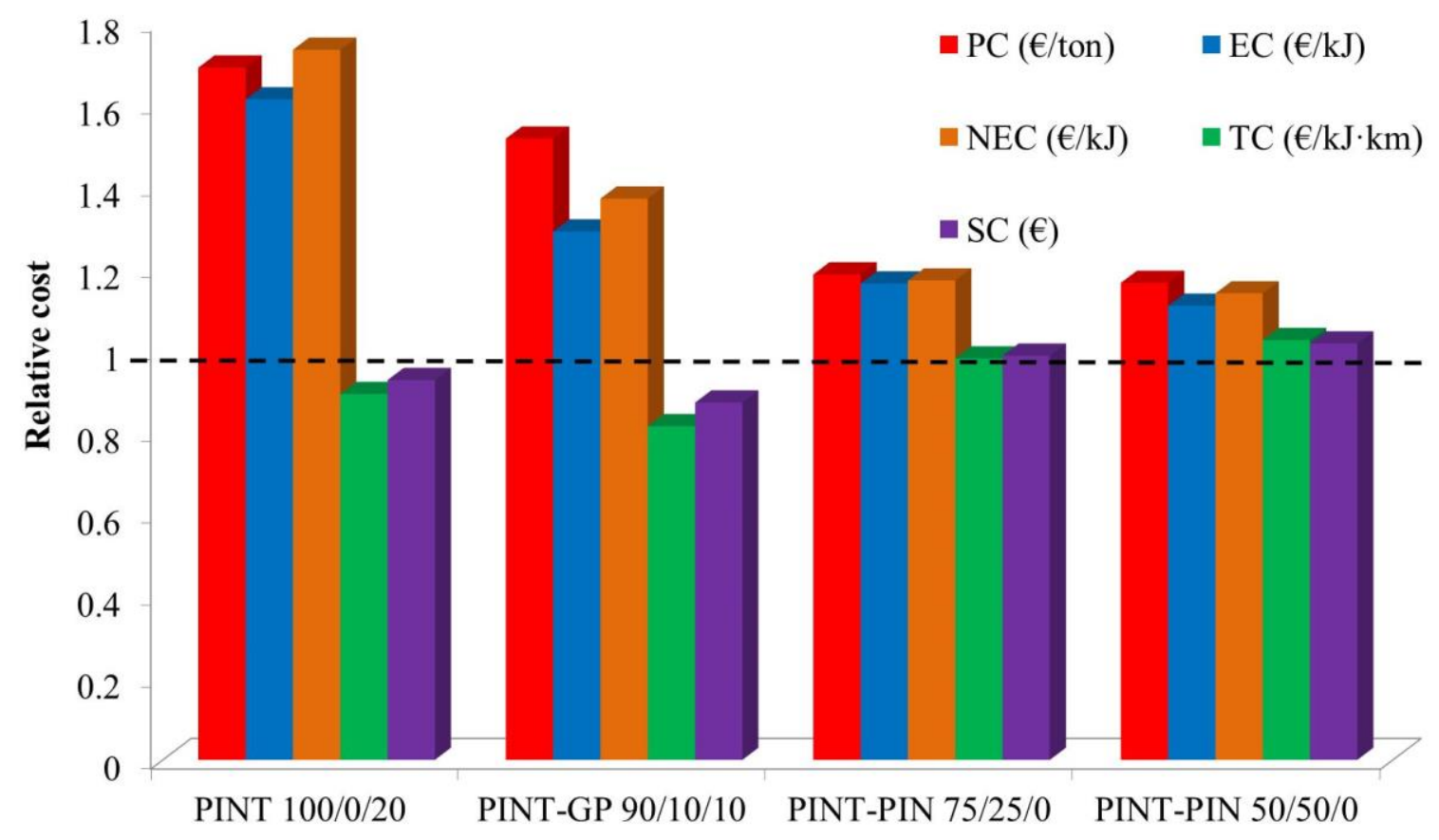

Figure 5. Cost analysis of the best obtained formulations relative to the cost of the reference sample (PIN 100/0/0). (For interpretation of the references to colour in this figure legend, the reader is referred to the web version of this article.) 